\title{
GOZAR OS GÉNEROS: PARA UMA ESCUTA QUEER DE NÃO-BINARISMOS DE GÉNERO
}

\section{Resumo}

Neste artigo, pretende-se explorar as vivências subjetivas, relacionais e sociais de sujeitos questionantes do binarismo de género. Tendo por base os estudos queer, partimos à exploração e desconstrução de mecanismos sociais opressores neste binarismo. Foram entrevistadas oito pessoas questionantes do binarismo de género e procedeu-se à análise temática (Braun e Clarke 2006) dos dados recolhidos. Emergiram dois temas: (i) processos de subjetivação - ao nível do self e da alteridade retratando as diversas dificuldades e conquistas; e (ii) «Sem um lugar que seja seu» - caracterização da opressão da heteronormatividade nas posições de sujeito e nos processos de genderização de contextos; temas estes que elucidam a desumanização experienciada pelo choque entre a desidentificação face ao binarismo de género e a obrigatoriedade de cumprir normas.

Palavras-chave Géneros, não-binarismo, queer, humano.

\section{Abstract}

To Enjoy Genders: for a queer listening of gender non-binaries

The present work aims to explore the subjective, relational, and social experiences of individuals who question the gender binarism. From a queer standpoint, we start exploring and deconstructing the oppressive social mechanisms of this binarism. We interviewed eight people who question the gender binarism and proceeded to the thematic analysis to systemize the collected data (Braun e Clarke 2006). Two themes emerged from this analyse: (i) subjectivation processes - at the level of the self and of the otherness, portraying the hardships and achievements; (ii) «Without a place of one's own»- characterization of the oppression of hetereonormativity in the subject positions and in the processes of genderization of contexts. These themes shed light to the dehumanizing experience of the clash between non-identifying with the gender binarism and the demand to obey the norms.

Keywords Genders, non-binarism, queer, human.

\section{Resumen}

\section{Gozar los Géneros: para una escucha queer de no-binarismos de género}

En este artículo, se pretende explorar las vivencias subjetivas, relacionales y sociales de sujetos cuestionantes del binarismo de género. Con base en los estudios queer, partimos a la explotación y desconstrucción de mecanismos sociales opresores en este binarismo. Se

* Centro de Psicologia da Faculdade de Psicologia e Ciências da Educação da Universidade do Porto, 4200-135 Porto, Portugal.

Endereço eletrónico: teresa.r.f.teixeira@gmail.com

** Centro de Psicologia da Faculdade de Psicologia e Ciências da Educação da Universidade do Porto, Portugal.

Endereço postal: R. Alfredo Allen, 4200-135 Porto.

Endereço eletrónico: nunoscarneiro@gmail.com 
entrevistó a ocho personas cuestionantes del binarismo de género, y se procedió al análisis temático (Braun e Clarke 2006) de los datos recogidos. Se plantearon dos temas: (i) procesos de subjetivación - a nivel del self y de la alteridad, retratando las diversas dificultades y conquistas; y (ii) «sin un lugar que sea suyo» - caracterización de la opresión de la heteronormatividad en las posiciones de sujeto y en los procesos de genderización de contextos; temas que elucidan la deshumanización experimentada por el conflicto entre la desidentificación frente al binarismo de género y la obligatoriedad de cumplir normas.

Palabras clave: Géneros, no binarismo, queer, humano.

Gozar - verbo in/transitivo - desfrutar, usufruir, divertir-se, ter um orgasmo, vir-se.

Adaptado de https://www.priberam.pt/dlpo/gozar

\section{Introdução}

No ensejo de acolher as (desafiantes) propostas de pensamento e de produção lançadas neste número temático, no presente artigo debruçamo-nos sobre as experiências de pessoas não identificadas com os binarismos de género ou identificadas com formas vivenciais, localizações e temporalidades que escapam, e/ou se opõem de modo ativo, a estes binarismos. Para tal, consideramos como proposta epistémica adequada a esse propósito o recurso a uma analítica queer.

Analisando o terreno social, apercebemo-nos de uma tendência para a compulsiva classificação da vivência humana maioritariamente assente em categorias de pertença dicotómicas, que produzem e mantêm hierarquizações e assimetrias nocivas à riqueza da diversidade humana (Levy 2004). Uma dicotomia a problematizar em particular diz respeito às categorias de pertença transgénero/cisgénero. Os termos «cis-sexual» e «cisgénero» surgem com intento de descentralizar o grupo dominante, expondo-o apenas como uma alternativa, e não a norma através da qual as pessoas trans são definidas (Koyama 2002). Fazemos nossas as palavras de Amara Moira quando refere «Cis: [como] o contrário de trans, seja lá o que isso signifique» $(2017,369)$, expressões que apenas indicam experiências fronteiriças, não tradutoras das vivências de todas as pessoas e que, portanto, só existem por nomeação e oposição na vontade do mutuamente exclusivo.

A transcendência dos géneros é, por inerência, uma transcendência de nós, um fazer-se e dizer-se milhões de géneros, de incontáveis e inimagináveis possibilidades na teia do Humano. Trata-se de uma permanente ação de que só uma política da diferença e uma oposição epistémica, ontológica e vivencial à essencialização identitarista podem dar conta na inteligibilidade humanizada de tal transcendência (Miskolci 2009). O pensamento queer mantém-se crítico em relação às grandes dicotomias e ao modo como determinados discursos veiculam determinadas ideias que servem de «verdades» para as sociedades (Oliveira 2010). Estas posições normativas não são naturais nem fixas, advêm de longas histórias de relações de poder e da sua manutenção (Levy 2004). 
Um processo normalizador a que se pretende dar especial enfoque neste trabalho é a sequência sexo-género-sexualidade. Ora, essa sequência é afirmada e reiterada a partir do momento em que nos identificam como «menina» ou como «menino», instalando-se um processo que, supostamente, deve seguir determinada direção (Louro 2004). Sendo que o «sexo» ainda é concebido como anterior à cultura, continua a ser-lhe atribuído um caráter imutável, a-histórico e binário, e por isso capaz de determinar o género e induzir a uma única forma de desejo. A relação entre o sexo do corpo, os papéis de género e a identidade de género tem sido imaginada como sendo rígida, mecânica e imitativa (Stryker 2006). Contudo, são as práticas discursivas que fazem com que aspetos dos corpos se convertam em definidores de género e de sexualidade e, como consequência, acabem por se converter em definidores do sujeito (Louro 2004).

O corpo não é naturalmente «sexuado», ele torna-se o que dele se costuma dizer e fazer através de processos culturais que utilizam a produção da sexualidade para manter relações de poder específicas (Spargo 1999) em que as normas regulatórias vêm indicar-lhes limites de sanidade, de legitimidade e/ou de coerência (Louro 2004). A ideia do corpo como algo «totalitário» e a «uniformidade» do seu sexo revela-se socialmente construído (Stryker 2006), evidente pela desobediência e subversão desta sequência.

\section{Movimentações de géneros}

O conceito de género tem vindo a contribuir para a produção de novos objetos de estudo, dando lugar a uma perspetiva crítica sobre a produção dos saberes em diversas disciplinas das ciências sociais (Amâncio 2003). Torna-se crucial entender a multiplicidade conceptual que o acompanha, entendê-lo como «um rizoma, [que] pode ser desterritorializado e reterritorializado de múltiplas formas e com inúmeras invocações» (Oliveira 2012, 51). O género, assim entendido, promove a abertura de possibilidades de conceber a sociedade, os seus mecanismos opressores e as possibilidades de o reconhecimento de novas formas de existir.

Butler (1990) foi das primeiras autoras a defender que não existe nada de autêntico ou natural no género, sendo este uma ficção cultural. O género representa o contínuo discurso da prática estruturada atualmente em torno do conceito de heterossexualidade como a norma das relações humanas. Este sistema normativo de heterossexualidade compulsória (Rich 1980) determina uma supressão da homossexualidade e discriminação das pessoas homossexuais (Oliveira 2012) que se instala no género, resultando numa falsa coerência de géneros aparentemente estáveis e vinculados aos sexos biológicos «apropriados» (Spargo 1999). Os estudos queer mantêm uma postura de resistência a este modelo, demonstrando a impossibilidade de qualquer sexualidade natural, colocando até em questão as categorias aparentemente não problemáticas como as de «homem»e «mulher» (Jagose 1996). 
A construção da coerência - que oculta as descontinuidades do género que se difundem nos contextos heterossexuais, bissexuais, gays e lésbicos, ou na sexualidade em geral - não parece decorrer do género - no qual, a rigor, nenhuma dessas dimensões de corporeidade significante se expressa ou reflete (Butler 1990). Acreditamos que personagens que transgridem o género e a sexualidade podem ser emblemáticas da pós-modernidade, pois a visibilidade e a materialidade desses sujeitos evidencia o caráter inventado, cultural e instável de todas as identidades (Vilela 2010). São significativas, ainda, por sugerirem concreta e simbolicamente possibilidades de proliferação e multiplicação das formas de género e sexualidade (Louro 2004), constituindo assim essas multidões queer, como lhes chamou Paul B. Preciado (2011).

A coerência é desejada, anelada, idealizada, o que constitui um efeito da significação corporal (Butler 1990). Por outras palavras, atos, gestos e desejos produzem o efeito de um núcleo ou substância interna, mas produzem-no na superfície do corpo, por meio do jogo de ausências significantes, que sugerem, mas nunca revelam, o princípio organizador da identidade como causa - são performativos (Butler 1990). O género pode ser assim concebido como um efeito performativo experienciado pelo indivíduo como a identidade natural, incitado pelas normas que nós materializamos, ou não, ou que materializamos de forma não expectável. Não nos comportamos de determinada forma por causa da nossa identidade de género, nós obtemos essa identidade através de padrões comportamentais, que sustentam as normas de género (Spargo 1999).

Encontramo-nos, assim, numa constante negociação com as normas e com o seu poder sobre nós. A teoria da performatividade do género constitui-se como uma teoria amoral, o seu propósito é enfraquecer a influência coerciva das normas na vivência de género, o que não se traduz em transcender todas essas normas, para a possibilidade de viver uma vida mais tolerável e autêntica (Butler 1990).

\section{A excisão do humano: obstáculos para expressividades não-binárias de género}

Podemos considerar que as propostas teóricas de Butler têm importantes implicações que contribuem para a formulação de novas perspetivas de ação política: «[por um lado,] usando as armas da teoria crítica, com a atenção focada nos discursos sociais; por outro lado, descentra[ndo] a política do single issue, pensando não num grupo específico [...] mas em coligações de que o queer é um exemplo» (Oliveira 2015, 12). A performatividade de género literalmente destrói o fundamento para movimentos políticos em que o objetivo é a liberação de naturezas reprimidas ou oprimidas, seja de género ou sexual, mas abre possibilidades de resistência e subversão encerradas pelas e nas políticas de identidade.

A determinação dos lugares sociais ou das posições dos sujeitos no interior de 
um grupo é referencial aos seus corpos - através dos quais os sujeitos são indiciados, classificados, ordenados, hierarquizados e definidos - a partir dos padrões e referências, das normas, valores e ideias da cultura (Butler 2004; Louro 2004). Entendemos como a heteronormatividade, enquanto prática regulatória do sexo, do género, e do desejo, estabelece as condições para a inteligibilidade do género, constituindo uma política da verdade, imbuída nas relações de poder e que (pré-)define o que contará e o que não contará como verdade. Neste sentido, de acordo com as normas vigentes, certos humanos são reconhecidos como menos do que humanos, e essa forma de reconhecimento, ou de não reconhecimento, torna a vida intolerável (Butler 2004).

Nesta procura de reconhecimento, fica evidente a homonormatividade, ou seja, práticas e discursos perpetuados por gays e lésbicas que suportam, em vez de resistir, esta heteronormatividade, numa tentativa de assimilação e aceitação social (Duggan 1994). Percebemos como a heteronormatividade e a homonormatividade têm o poder de delimitar o que é inteligível da cidadania (sexual), fazendo da cidadania uma noção excludente. O próprio conceito de cidadania acaba por ser caracterizado pela exclusão baseada nas normas sexuais e de género (Oliveira, Costa e Carneiro 2014).

O desafio passa a ser o de compreender como se criam as diferenças e como elas atuam no presente, defendendo uma mais ampla mudança social, já não apenas no sentido de afirmar a «diferença» sexual, mas de lutar ativa e radicalmente contra qualquer forma de opressão (Carneiro 2009), difundindo o conhecimento necessário para fazer frente aos processos normalizadores que justificam o uso das diferenças como marcadores de hierarquia e opressão (Miskolci 2009).

As categorias sexuais e de género existem e servem uma função na sociedade, ignorá-las seria ingénuo e perigoso, correndo-se mesmo o risco de deixar de saber distinguir e nomear grupos sociais discriminados (Maia, Louro e Vitorino 2009). Contudo, a sua desconstrução e relativização deve sempre acompanhá-las, pois desistir de fazer a sua crítica em nome de uma «visibilidade» aceitável (aos olhos estreitos e ofuscados da heteronormatividade), é derrotar à partida um projeto que poderia ser emancipatório (Maia, Louro e Vitorino 2009).

A teoria queer não é uma resposta rápida e concisa e, talvez por isso, ainda não estejamos preparadxs ${ }^{1}$ para compreender as suas implicações, não como a solução final, mas como uma abertura para as possibilidades quase infinitas à disposição do ser humano. Acreditamos, pois, que é por ser distintivamente emancipadora e libertadora que a teoria queer concebe possibilidades políticas de dar visibilidade e protagonismo ao sujeito individual, promovendo deste modo a diversidade (Nogueira e Oliveira 2010).

Ao longo do presente trabalho, optámos pela utilização de «X», um recurso a um signo que tenta contornar o universal masculino, apenas uma das opções possíveis e mais contempladoras das possibilidades de diversificação designante de sujeitos, ainda que reconhecendo não haver um signo que satisfaça inteiramente tal intenção. 


\section{Método}

No presente estudo, procura-se explorar como são as vidas de pessoas questionantes do binarismo de género, seja porque não se identificam com o binarismo de género, seja porque se identificam com o não-binarismo de género, tendo sido este o único critério para o recrutamento das pessoas a entrevistar. Pretende-se desvelar conceções discursivamente diferentes surgidas a propósito destes binarismos/normas (Objetivo 1), e tomar conhecimentos das diferentes produções discursivas por parte desta população desafiante a respeito das suas vivências (Objetivo 2), reconhecendo de forma mais compreensiva os constrangimentos e obstáculos, e benefícios e liberdades vivenciadas a diferentes níveis dos seus trajetos de vida (Objetivo 3).

Realizaram-se entrevistas semiestruturadas, durante 2016, a oito pessoas com idades compreendidas entre os 19 e os 51 anos. $^{2} \mathrm{O}$ recrutamento foi realizado por conveniência e recorrendo, primeiro, a informantes privilegiadxs que indicaram as primeiras pessoas entrevistadas e, num momento seguinte, recorrendo ao método bola de neve. Estxs participantes expressam uma grande variabilidade de autoidentificações, por vezes optando por designações binárias e normativas, p. ex., «homem», outras desafiavam à partida estas designações, p. ex., «identifico-me com ter um útero porque o sinto todos os meses», «Pessoa não-binária, demiboy, whatever...»

O procedimento utilizado na análise dos dados recolhidos foi a análise temática, ${ }^{3}$ por ser a abordagem mais congruente com os aspetos teóricos que constituem a deste trabalho, permitindo-nos analisar os discursos na lógica interseccional pretendida.

\section{Análise e Discussão dos Resultados}

\subsection{Processos de subjetivação}

A presente análise permitiu compreender uma diversidade de posicionamentos que traduzem modos subjetiv(ad)os de experienciar a transgressão representada pela não-identificação com o binarismo de género, a que chamámos processos de subjetivação. Recorre-se à ideia butleriana (Butler 1997) que, tendo como pano de fundo o paradoxo sempre inerente à subjugação (constituímo-nos porque nos subjugamos e vice-versa), permite entender a subjetivação como processo. Entendem-se assim estes processos como essa genealogia, porque faz do sujeito uma

São utilizados nomes fictícios, que tentam ser neutros quanto ao género.

Ver a explicitação mais extensa destas fases segundo Braun e Clarke (2006), que aqui apenas nomeamos: familiarização com os dados; produção de códigos iniciais; pesquisa dos temas; revisão dos temas; definição e nomeação dos temas; e produção do relatório final. 
categoria crítica e necessariamente linguística encerrando uma matriz identitária e em busca permanente de um lugar.

Nesta perspetiva, foi possível dar inteligibilidade a dois níveis experienciais que encontramos e designamos através da análise: Selfe Alteridade. Se a subjetivação tal como antes apresentada remete para as estruturas de poder, o Self remete para a individualização da experiência nessas estruturas e a Alteridade remete para a não referencialidade do self, ou seja, a impossibilidade de identificação com tudo o que (ainda) não se experienciou (Butler 1997).

\section{Self}

Nos palcos da quebra das expectativas normativas de género, a reação subjetiva primária tende a ser a de uma negação imposta a si mesmx. Pela opressão que recai sobre quem desafie as normas de género, compreende-se que as experiências pessoais associadas a este desafio se desenhem numa vergonha que configura a subjetivação como efeito do regime da normatividade de género (Costa, Oliveira, e Nogueira 2010). Alguns discursos remetem também para um momento precoce em que se reconhece a vivência pessoal como fora da heteronormatividade e, com isto, uma crença na sua impossibilidade (Costa, Oliveira, e Nogueira 2010):

É melhor não pensar nisto, e não tentar resolver isto... como é que as pessoas vão reagir, e [...] essa necessidade de ser aceite e pertencer a um grupo e ter achado que por isso não poderia. (Mel)

Identificava-me com aquilo que via, que era um menino! Mas também tinha noção que não era bem isso, que havia coisas que me invalidavam nessa categoria. (Mizé)

Quando iniciam um caminho de procura e descoberta de novas possibilidades de existir, a maior parte dxs participantes relata a experiência de não-identificação/de desidentificação com as categorias de género socialmente disponíveis (Grave 2016). O esforço para viver de forma a manter uma relação crítica e transformativa com essas normas pode ser doloroso e até intolerável: o «eu» torna-se, até certo ponto, desconhecido, ameaçado de desintegração, por vezes com associação ao sentimento de se viver uma vida intolerável na ausência do reconhecimento social (Butler 2004).

Comecei a questionar seriamente [...] tinha uma noção muito a preto e branco das coisas, uma noção de que isto é que é ser homem e isto é que é ser mulher [...] e a dada altura foi eu não consigo, I can't deal with this right now. (Mel)

Outro subtema relevante no campo dos processos de subjetivação é a relação com o corpo. Esse corpo que continua sendo reiterado como norma e como verdade equívoca instaurada pela Modernidade (Vilela 1998). Aquilo a que normalmente chamamos o sexo do corpo, é revelado como consistindo de inúmeras 
partes - cromossómico, anatómico, reprodutivo, morfológico -, como variabilidade de agregações viáveis e possíveis num muito mais além de dois polos (Stryker 2006; Fausto-Sterling 2012). Nesta linha de pensamento, algumas pessoas entrevistadas relatam diferentes experiências na re/significação dos (seus) corpos, experiências que emergem por vezes como principal contribuinte para o questionamento do binarismo de género, quando a considerada direção legítima de transformação do corpo não traduz a experiência pessoal. Leia-se este excerto:

[aos 8 anos] quero tirar a camisola, mas «não podes porque não és um menino», mas posso, porque é que não posso? O que é que distingue, não andamos aqui a baixar as calças uns aos outros para saber. (Mizé)

Há alguns discursos que frisam do modo ainda mais crítico as normas da corporalização, entendendo-as como não sendo naturais nem seguras e, portanto, sendo discutíveis através de constante desafio, subversão e ressignificação (Louro 2004):

muita gente que se vê como rapaz num corpo de rapariga vê-se como recipiente. Eu comecei a ver o meu corpo como uma coisa que eu tenho de gostar sem ser uma prisão, [...] o corpo deve ser a nossa proteção. (Noah)

Todos estes processos de subjetivação são fulcrais para que xs participantes alcancem e mantenham uma aceitação de si, em detrimento da assimilação na normatividade de género, o que passa pela procura de um lugar de reconhecimento da subjetividade. Esta aceitação pela distinção face à normatividade é sentida e relatada como uma conquista marcante:

para mim, a minha maior conquista foi poder perceber o que sou [...] a partir do momento que percebes aquilo que és e te aceitas como és, tu ficas muito relaxado, ficas em paz contigo próprio, e isso é muito bom. (Noah)

Importa refletir que esta aceitação pessoal da diferença, enquanto distinção processual face às categorias sociais disponíveis na trajetória vital destas pessoas, não configura uma afirmação identitária: mais do que isso, tal diferença é entendida por elas como mais fundamental do que a identidade (Butler 2009). Por isso se torna crucial interrogar os termos pelos quais a vida é constrangida e de que modo se pode fazer emergir e visibilizar modos de subjetivação que resistem ao assimilacionismo, ou seja, modos mais humanos de viver(-se) (Butler 2004).

\section{Alteridade}

Numa primeira abordagem, emergiu algum consenso sobre a angústia experienciada aquando da possibilidade de revelar os questionamentos de género aos 
pares e familiares, angústia que pode adiar, senão impossibilitar, uma vivência de si sentida como autêntica. Um exemplo ilustrativo:

pensar que a minha família não me poderia aceitar como eu sou, eu acho que é uma coisa que mete medo, [...] é pensar que [...] as pessoas que consideras mais próximas nunca te poderão ver como tu és [...] e não como aquela pessoa que queriam que tu fosses. (Noah)

Este medo encontra, pelo discurso das pessoas entrevistadas, corroborações ao longo das suas vidas em relatos sobre inúmeros episódios de rejeição, que vão de uma não-legitimação das experiências de género até à sua ostracização direta:

eu era um bocado a aberração no liceu... e por me acharem um bocado efeminado e com todas as implicações que isso tinha num contexto de gozo adolescente. (Alex)

A possibilidade de viver autenticamente é acompanhada, nos discursos analisados, por um medo persistente de sofrer repercussões nocivas, muitas vezes acreditando e aceitando a impossibilidade de se conceber como sujeito para além das normatividades vigentes e sofrendo situações de rejeição, de violência, de negação e de invisibilidade. Trata-se, então, de ser sujeito de uma reiteração da alteridade, que emerge na análise das relacionalidades que os discursos veiculam.

Surge aqui a importância da existência de contacto com novos e diferentes tipos de vivência fora da normatividade. Esta contemplação surge como fulcral na experiência dxs participantes e no seu percurso de subjetivação no que diz respeito à sua identificação para além do binarismo de género, representando um momento de abertura para possibilidades múltiplas e por isso não binárias de vivência do género:

Fui começando a construir uma ideia um bocado diferente daquela que tinha, do preto e branco, ok [...] se calhar há aqui um espectro... e depois também entre nets e etecetera obviamente abro um bocado a cabecinha. (Mel)

Apesar desta abertura a outras possibilidades de se fazer sujeito, os processos de subjetivação não ocorrem num vácuo, mas antes em espaços de influências externas. Tais influências e pressões para o encontro consigo e com outrem conduzem a uma continua e recíproca didática de si, que xs participantes se sentem impelidxs a desenvolver como que justificando as configurações e os sentidos das suas vivências. Assim, começam por surgir reflexões sobre o impacto que múltiplas instâncias sociais e culturais têm na (re)afirmação das normas, postos em ação pelas famílias, pelas escolas, pelos meios de comunicação social, etc. (Foucault [1976] 1994; Louro 2004). Estas instâncias controlam e ditam, afinal, a construção subjetiva na saga opressiva e excludente da heteronormatividade, que se tornam geradoras de um marcado sofrimento psicológico: 
estava habituada a poder ser eu [...] entro para a escola e eles instituem-me que eu tenho de ser uma rapariga, entre aspas, que tenho de agir de certa forma, ter certos comportamentos, que tenho de ser doce, tenho de ser carinhosa com as pessoas, mesmo que por dentro não me sinta assim. (Noah)

a definição que as pessoas têm de homem e de mulher tem muito que ver depois com aquilo que nos é transmitido pelos pais, principalmente, depois por aquilo que vivencias na escola e com os grupos com que te dás. [...] vamos absorvendo a sociedade à volta. (Eli)

As pessoas entrevistadas também caracterizaram outro passo importante que acaba por informar e impactar os seus processos de subjetivação e que passa pelo momento de partilha destes seus questionamentos com as pessoas mais próximas. Na sua maioria, relatam a necessidade de adotar uma espécie de papel de educação sobre essas pessoas. Para alguns e algumas participantes é até entusiasmante poderem promover a diversidade de conceções e vivências de género para pessoas que não o teriam considerado anteriormente:

falo destas questões sempre que é pertinente esclarecer uma existência que ainda não é assim tão óbvia para a maior parte. (Mizé)

esforcei-me bastante para tentar explicar às pessoas como é que funcionava [...] mudar a mentalidade de algumas pessoas, o que é muito bom, eu percebi que [...] estou a ajudar essas pessoas e as pessoas que essas pessoas possam encontrar no futuro. (Noah)

Por oposição a este «entusiasmo didático», outrxs participantes, apesar de compreenderem a grande falta de informação e discussão sobre géneros não-binários, consideram este papel como desmoralizante, pois continuam a sentir-se obrigadxs a legitimar a sua existência:

tu tens de fazer um bocado o papel de educador, e tens de explicar e ok se calhar eu vou-te mandar umas coisas, uns links e assim... e por um lado é assim, eu entendo, mas por outro eu gostava de não ter de fazer este trabalho! (Mel)

\section{5. «Sem um Lugar que seja seu $»^{4}$}

O não-lugar a que são muitas vezes remetidas (Grave 2016; Rodrigues 2016) parece sensibilizar as pessoas entrevistadas para questões interseccionais, o que

4 O tema em análise é assim designado como alusão à conhecida obra A room of one's own, de Virgínia Woolf. 
lhes permite fugir à generalização abusiva do determinismo biológico e essencialismo, procurando expandir o pensamento acerca do género ao reafirmar a natureza «multiplicativa interseccional» e o impacto do contexto.

Seguidamente, são apresentados os subtemas: posições dos sujeitos e a genderização de contextos; que procuram caracterizar a experiência destes não-lugares.

\subsection{Posições de Sujeito}

A emergência e a fixação de lugares sociais dá-se a partir de padrões de referência normativos que intentam e produzem a classificação de subjetividades (Louro 2004), tendo por base operações de poder, que não são asseguradas pelo direito, pela lei, pela punição, mas pela normalização e pelo controlo que em nós atuam e que fixam ideias e representações sobre nós (Foucault 1975/1999). É assim que o enquadramento binário permite que grupos dominantes policiem categorias de forma a reificarem essa mesma dominação e, em complemento, a subordinação de modos e de posições de existência não-normativizáveis.

Quando se considera a existência de limites das políticas de verdade, percebemos como persistem dúvidas de como reconhecer sujeitos que fogem à heteronorma, e até de que forma este reconhecimento precisa de existir ao nível institucional, legal e cultural (Butler 2009). No âmbito social, permanece a suposição de que todxs temos que fazer as mesmas «escolhas», seguir trajetórias de vida preconcebidas - e.g., de casar, ter filhos - que se apresentam simultaneamente como ideias e ideologias que privilegiam a heterossexualidade em detrimento de todas as outras orientações sexuais. Este grau de institucionalização de expectativas continua a marcar pela impossibilidade as vivências fora da heteronorma (Costa, Oliveira, e Nogueira 2010).

Assim, xs participantes relatam uma presença quotidiana e constante da pressão de expectativas predeterminadas sobre o género e de uma inteligibilidade de e sobre si mesmxs, bem como o combate persistente a esta sujeição:

mas tu já sabes? que és homem, ou que és mulher, ou que és o quê? Porquê? E porque não? [...] Mas nunca foste assim? [...] querem logo uma definição logo à partida. (Mel)

Os sujeitos entrevistados relatam ter que lidar com ameaças à sua integridade física e psicológica, a tal ponto que por vezes optam por ceder às pressões, levando a um sentimento de que as suas experiências não têm valor e de invalidação destas experiências:

eventualmente criei uma ideia na minha cabeça de que quando crescer vou ser um homem, porque assim a minha mãe vai aceitar-me, toda a sociedade vai aceitar-me [...]. Apesar de eu continuar a gostar de me ver como rapariga. (Noah) 
A análise das diferentes posições de sujeito deu a compreender que elas são muitas vezes des/construídas através de subjetivações transitórias.

Como temos vindo a refletir, instâncias como as ciências biomédicas e a psiquiatria, a escola e a família continuam a promover a negação de sexualidades e de géneros errantes (Foucault [1976] 1994). Apesar de parecer existir nestes discursos um prazer em exercer um poder que questiona e fiscaliza, também parece haver um prazer que se incandesce no escape a esse poder, contrapondo-o e travestindo-o. Algumas das pessoas participantes relataram o prazer da subversão de expectativas de género, quer pela «novidade», quer pelo «choque» provocado nas interações sociais:

eu costumo dizer que gosto tanto de mulheres que eu queria [...] vestir-me como elas. Mas só de vez em quando! Senão perde o encanto, no meu ponto de vista, perde o encanto. (Cris)

a ideia de estar a perverter uma expectativa também é minimamente interessante, [...] começa por ser uma questão pura e simplesmente de uma pessoa se embelezar, [... ] se calhar é andar arranjado de uma maneira que ainda não é muito expectável que um homem ande. (Alex)

Contudo, muitos destes momentos de transgressão são circunscritos a lugares que xs participantes consideram seguros, sendo que a falta de reconhecimento relatada é sentida como uma forma de legitimação da violência contra expressividades não-normativas e que conduz ao self-policing, e a dissimulação destas expressividades:

[se] for dar aulas, claro que tiro o verniz das unhas, e não devia ter de tirar... ou se calhar não tenho, mas não devia achar que tenho de tirar, mas acho... até é uma autorrepressão. (Alex)

\subsection{Genderização de Contextos}

O segundo subtema é relativo à caraterização que xs participantes fazem do lugar social em que se encontram, problematizando o seu impacto para uma vivência autêntica e livre. Continuam a encontrar no dia-a-dia situações que negam a expressividade das suas vivências, numa dificuldade de apropriação de espaços públicos, assim como pela linguagem e pela terminologia dicotómica em que somos socializados (Costa, Oliveira, e Nogueira 2010):

por exemplo, casamentos, como é que tu vais? Como é que tu vais se não... se achas que as regras do ser homem e do ser mulher, como é suposto uma pessoa ir vestida? (Mel) 
Com efeito, a reapropriação e a ressignificação do(s) espaço(s) público(s) surgem como ações necessárias à visibilidade de um pluralismo de vozes e singularidades que nos tornam a todxs pessoas (Costa, Oliveira, e Nogueira 2010; Butler 2015). O não reconhecimento de uma vivência do género para além do binarismo imposto faz com que a violência contra os sujeitos considerados transgressores seja legitimada e até defendida.

A sociedade em que vivemos, marcada pelo genderismo e pelas múltiplas e incessantes violências de género, de que a transfobia é particularmente elucidativa, sustenta-se em múltiplos procedimentos administrativos que dificultam, quando não negam e inviabilizam, as vidas de quem atravessa as fronteiras sociais da imposição de género atribuída à nascença com base no suposto «sexo» (Stryker 2008; Spade 2015). Ficou assim evidente que xs participantes continuam a sentir que não são reconhecidxs na sua cidadania, particularmente quando sofrem experiências de cis-sexismo/cisgenderismo: ${ }^{5}$

estou a fazer um questionário e chego à pergunta em que me perguntam se és um homem ou uma mulher, lol! Onde é que está a minha terceira opção? o facto de eu não ter uma pila é tão ou mais relevante que a necessidade de uma educação. [...] Acho que são barreiras de invalidação graves o suficiente. (Mizé)

Pessoas transgénero/questionantes do binarismo de género tipicamente têm falhas de suporte que membros da sociedade aceites usufruem automaticamente, e sem questionar a sua viabilidade (Stryker 2008). Todas estas experiências discriminatórias passam, acima de tudo, pela organização de uma sociedade onde o género é pensado de forma rígida e binária, e por isso excludente. Esta recusa de uma existência válida invisibiliza pessoas com identificações não-binárias; fazendo recair sobre elas essa violência maior, que é a «violência de inexistir» (Carneiro 2009, 2013):

eu diria que esta incompreensão do não-binarismo, $[\ldots]$ a heteronormatividade no geral é um grande problema [...] porque as pessoas esquecem-se que tudo o resto pode ser válido também... por estar a pôr em causa os privilégios delas enquanto pessoas validadas, pode torná-las muito violentas. (Mizé)

\section{Reflexividades}

A presente análise das diferentes conceções dxs participantes face ao binarismo de género e às suas vivências fora deste binarismo, revestida pelas propos-

Uma estrutura ideológica que marginaliza, desvaloriza e/ou anula as experiências das pessoas em que a designação do sexo aquando do nascimento não corresponde aquela a que a pessoa se sente pertencer (Rodrigues 2016). 
tas conceptuais aqui acolhidas, deu a perceber que as pessoas que transcendem as normas de género são constantemente posicionadas fora da esfera da humanidade (Oliveira, Costa, e Carneiro 2014).

Eis-nos, penando neste não reconhecimento do humano, perante formas de um não-pensamento em nome do normativo (Butler 2009). As expressividades de género não conformes estão, assim, no constante limbo do limite de serem consideradas menos humanas ou mesmo não-humanas (Oliveira, Costa, e Carneiro 2014). Neste sentido, é necessário desenvolver ativamente a reflexão sobre a categoria «minoria» como algo que distingue entre quem tem ou não tem direito ao (re)conhecimento da cidadania, sob pena de permanecermos numa cidadania (sexual) sob suspeita (Oliveira 2013). Torna-se urgente formular novas conceções para pensar a normatividade que nos permitam apreciar compreensivamente o mundo em que vivemos (Butler 2009).

A partir de uma abordagem crítica queer, compreendemos como é crucial desconstruir discursos e transformá-los, tanto na esfera do social, quanto na esfera da instauração disciplinar e disciplinante de saberes (Parker 1999). A questão a suscitar em permanência é a de como o poder configura o campo em que alguns sujeitos se tornam possíveis, merecedores de existência, de proteção e passíveis de luto e outros não (Butler 2009), o que não pode ser reflexo de um problema de identidade, nem sequer um problema do sujeito. Defendemos assim uma prática de um descobrir desconstrutivo, que funcione opondo-se à definição e à prescrição, pois é urgente perceber como os problemas jogados sobre as expressividades não-normativas são produzidos, em vez de tentar encontrá-los (Parker 1999).

Assim, inscrever e libertar as expressividades múltiplas e ilimitadas de género implica necessariamente uma atenção crítica permanente às próprias operações de poder, incluindo os efeitos orquestrados pelos poderes inerentes à formação de sujeito (Butler 2009). Ao colocar em questão as classificações e seus enquadramentos, e ao examinar a transgressão e o atravessamento das fronteiras, podemos potenciar a exploração da ambiguidade e da fluidez (Louro 2001).

Num momento em que as certezas falham, em que os modelos se mostram limitados e em que as fórmulas são inoperantes e indesejáveis, num momento em que continua a ser impossível esgotar as questões, é relevante empreender esta «reviravolta epistemológica». Pretende-se promover novas formas de conhecer e aprender, em que a dúvida deixa de ser desconfortável e nociva para se tornar estimulante e produtiva; em que as questões insolúveis não cessam as discussões, mas, em vez disso, sugerem a busca de outras perspetivas. A teoria queer, acima de tudo, enaltece como podemos encontrar no questionamento, na desnaturalização e na incerteza estratégias férteis e criativas para pensar qualquer dimensão da existência (Louro 2004).

Nisto residirá a possibilidade de gozar os géneros, de com eles brincar, de neles encontrar consolo e gozo, de neles e com eles gozar o que nos assiste em Humanidade. 


\section{Referências bibliográficas}

Amâncio, Lígia. 2003. «O género no discurso das ciências sociais». Análise Social 38 (168): 687-714. Disponível em https://www.jstor.org/stable/41011822

Braun, Virginia, e Victoria Clarke. 2006. Using thematic analysis in psychology. Qualitative Research in Psychology, 3 (2): 77-101. DOI: 10.1191/1478088706qp063oa

Butler, Judith. 1990. Gender trouble: Feminism and the subversion of identity, ed. rev. New York: Routledge.

Butler, Judith. 1997. The Psychic Life of Power: Theories in Subjection. Stanford, CA: Stanford University Press.

Butler, Judith. 2004. Undoing gender. New York: Routledge.

Butler, Judith. 2009. Frames of war: when is life grievable? London: Verso.

Butler, Judith. 2015. Notes Toward a Performative Theory of Assembly. Cambridge, MA: Harvard University Press. DOI: https://doi.org/10.4159/9780674495548

Carneiro, Nuno Santos. 2009. «Homossexualidades» uma psicologia entre ser pertencer e participar. Porto: Livpsic.

Carneiro, Nuno Santos. 2013. «Contra a 'violência de inexistir': psicologia crítica e diversidade humana». Psicologia \& Sociedade 25 (1): 40-47. DOI: https://doi.org/10.1590/S010271822013000100006

Costa, Carlos Gonçalves, João Manuel Oliveira, e Conceição Nogueira. 2010. «Discursos das pessoas LGBT». In Estudos sobre a discriminação em função da orientação sexual e da identidade de género, editado por Conceição Nogueira e João Manuel Oliveira, 211-242. Lisboa: CIG - Comissão para a cidadania e igualde de género.

Duggan, Lisa. 1994. «Queering the state». Social Text 39: 1-14. DOI: https://doi.org/10.2307/ 466361

Koyama, Emi. 2002. «Cissexual/Cisgender: decentralizing the dominant group». Eminism. org. Disponível em http://www.eminism.org/interchange/2002/20020607-wmstl.html

Fausto-Sterling, Anne. 2012. Sex/Gender: Biology in a social world. New York \& London: Routledge.

Foucault, Michel. (1975) 1999. Vigiar e Punir: nascimento da prisão. 20. a ed. Tradução de Raquel Ramalhete. Petrópolis: Editora Vozes.

Foucault, Michel. (1976) 1994. História da sexualidade I: A vontade de saber. Tradução de Pedro Tamen. Lisboa: Relógio D'Água Editores.

Grave, Rita Guerra. 2016. «Desidentificações de género: discursos e práticas». Tese de mestrado. Faculdade de Psicologia e Ciências da Educação da Universidade do Porto, Porto.

Jagose, Annamarie. 1996. Queer Theory: an introduction. New York: New York University Press.

Levy, Teresa. 2004. «Crueldade e crueza do binarismo». In Indisciplinar a teoria: estudos gays, lésbicos e queer, editado por António Fernando Cascais, 183-214. Lisboa: Fenda.

Louro, Guacira Lopes. 2001. «Teoria queer - uma política pós-identitária para a educação». Estudos Feministas 2, 541-553. DOI: https://doi.org/10.1590/S0104-026X2001000200012

Louro, Guacira Lopes. 2004. Um corpo estranho: ensaios sobre a sexualidade e teoria queer. Autêntica: São Paulo.

Maia, Bruno, Patrícia Louro, e Sérgio Vitorino. 2009. "Queer, ou a crítica da 'política do possível'». ex aequo 20: 133-136.

Miskolci, Richard. 2009. «A teoria queer e a sociologia: o desafio de uma analítica da normalização». Sociologias 21: 150-182. DOI: https://doi.org/10.1590/S1517-4522200900010 0008 
Moira, Amara Rodovalho. 2017. «O cis pelo trans». Estudos Feministas 25 (1): 365-373. DOI: http://dx.doi.org/10.1590/1806-9584.2017v25n1p365

Nogueira, Conceição, e João Manuel Oliveira. 2010. «Desafiar o futuro». In Estudos sobre a discriminação em função da orientação sexual e da identidade de género, editado por Conceição Nogueira e João Manuel Oliveira, 267-276. Lisboa: Comissão para a Cidadania e Igualdade de Género.

Oliveira, João Manuel. 2010. «Orientação sexual e identidade de género na psicologia: notas para uma psicologia lésbica, gay, bissexual trans e queer». In Estudos sobre a discriminação em função da orientação sexual e da identidade de género, editado por Conceição Nogueira e João Manuel Oliveira, 19-44. Lisboa: Comissão para a Cidadania e Igualdade de Género.

Oliveira, João Manuel. 2012. «O rizoma 'género': cartografia de três genealogias».e-cadernos ces 15: 33-54. DOI: https://doi.org/10.4000/eces.962

Oliveira, João Manuel. 2013. «Cidadania sexual sob suspeita: uma meditação sobre as fundações homonormativas e neo-liberais de uma cidadania de 'consolação'». Psicologia \& Sociedade 25 (1): 68-78. DOI: https://doi.org/10.1590/S0102-71822013000100009

Oliveira, João Manuel. 2015. «Tumultos de género: os efeitos de Gender trouble em Portugal». Periódicus 3 (1): 6-18. DOI: https://doi.org/10.9771/peri.v1i3.12844

Oliveira, João Manuel, Carlos Gonçalves Costa, e Nuno Santos Carneiro. 2014. «Problematizando a Humanidade: para uma psicologia crítica feminista queer». Annual Review of Critical Psychology 11: 59-77. Disponível em https://discourseunit.com/annual-review/11-2014/

Parker, Ian. 1999. «Deconstruction and Psychoterapy». In Deconstructing psychotherapy, editado por Ian Parker, 1-18. Sage: London.

Preciado, Beatriz [Paul]. 2011. «Multidões queer: Notas para uma política dos 'anormais'». Revista Estudos Feministas 19 (1): 11-20. DOI: https://doi.org/10.1590/S0104-026X2011 000100002

Rich, Adrienne. 1980. «Compulsory heterosexuality and lesbian existence». Signs 5(4): 631660. DOI: https://doi.org/10.1086/493756

Rodrigues, Liliana. 2016. «Viagens Trans(Género) em Portugal e no Brasil: Uma Aproximação Psicológica Feminista Crítica». Tese de Doutoramento. Faculdade de Psicologia e Ciências da Educação da Universidade do Porto, Porto.

Spargo, Tamsin. 1999. Foucault y la teoria queer. Barcelona: Gedisa Editorial.

Spade, Den. 2015. Normal life: Administrative violence, critical trans politics, and the limits of law. Durham \& London: Duke University Press. DOI: https://doi.org/10.1215/978082 2374794

Stryker, Susan. 2006. «(De)Subjugated Knowledges: An Introduction to Transgender Studies». In The Transgender Studies Reader, editado por Susan Stryker e Stephen Whittle, 1-17. Routledge: New York.

Stryker, Susan. 2008. «Transgender History, Homonormativity, and Disciplinarity». Radical History Revieww 100: 145-157. DOI: https://doi.org/10.1215/01636545-2007-026

Vilela, Eugénia. 1998. Do corpo equívoco: reflexões sobre a verdade e a educação nas narrativas epistemológicas da Modernidade. Coimbra: Angelus Novus.

Vilela, Eugénia. 2010. Silêncios tangíveis: Corpo, resistência e testemunho nos espaços contemporâneos de abandono. Porto: Afrontamento - Coleção Biblioteca de Filosofia, 20. 
Teresa Teixeira. Mestre em Psicologia Clínica pela Faculdade de Psicologia e Ciências da Educação da Universidade do Porto. Gestora de formações no âmbito da Igualdade de Género, Educação, Cidadania, Orientação Sexual e Identidade de Género no projeto no quadro de financiamento Portugal 2020, Programa Operacional Inclusão Social e Emprego (3.15 - Formação de Públicos Estratégicos; eixo prioritário 3 - Promover a inclusão social e combater a pobreza e a discriminação), apoiado financeiramente pela União Europeia.

Endereço eletrónico: teresa.r.f.teixeira@gmail.com

Nuno Santos Carneiro. Doutorado em Psicologia pela Faculdade de Psicologia e Ciências da Educação da Universidade do Porto. Investigador no Centro de Psicologia da Universidade do Porto, tendo inúmeros trabalhos publicados, nacional e internacionalmente, relacionados com estudos LGBT, perspetivas críticas, teoria queer, entre outros domínios de interesse. Psicoterapeuta com longa experiência junto de pessoas LGBTQ+ numa linha de intervenção culturalmente sensível.

Endereço eletrónico: nunoscarneiro@gmail.com

Artigo recebido a 15 de maio e aceite para publicação em 30 de agosto de 2018. 
